Article

\title{
Connecting the Morphological and Crystal Structural Changes during the Conversion of Lithium Hydroxide Monohydrate to Lithium Carbonate Using Multi-Scale X-ray Scattering Measurements
}

\author{
Greeshma Gadikota \\ Department of Civil and Environmental Engineering, Environmental Chemistry and Technology Program, \\ University of Wisconsin, Madison, WI 53706, USA; gadikota@wisc.edu; Tel.: +1-857-253-8724
}

Received: 25 August 2017; Accepted: 11 September 2017; Published: 14 September 2017

\begin{abstract}
While $\mathrm{CO}_{2}$ storage technologies via carbon mineralization have focused on the use of earth-abundant calcium- and magnesium-bearing minerals, there is an emerging interest in the scalable synthesis of alternative carbonates such as lithium carbonate. Lithium carbonate is the carbonated end-product of lithium hydroxide, a highly reactive sorbent for $\mathrm{CO}_{2}$ capture in spacecraft and submarines. Other emerging applications include tuning the morphology of lithium carbonates synthesized from the effluent of treated Li-bearing batteries, which can then be reused in ceramics, glasses, and batteries. In this study, in operando Ultra-Small-Angle, Small-Angle, and Wide-Angle X-ray Scattering (USAXS/SAXS/WAXS) measurements were used to link the morphological and crystal structural changes as lithium hydroxide monohydrate is converted to lithium carbonate. The experiments were performed in a flow-through reactor at $\mathrm{P}_{\mathrm{CO}_{2}}$ of $1 \mathrm{~atm}$ and at temperatures in the range of $25-500{ }^{\circ} \mathrm{C}$. The dehydration of lithium hydroxide monohydrate to form lithium hydroxide occurs in the temperature range of $25-150{ }^{\circ} \mathrm{C}$, while the onset of carbonate formation is evident at around $70{ }^{\circ} \mathrm{C}$. A reduction in the nanoparticle size and an increase in the surface area were noted during the dehydration of lithium hydroxide monohydrate. Lithium carbonate formation increases the nanoparticle size and reduces the surface area.
\end{abstract}

Keywords: lithium hydroxide monohydrate; lithium hydroxide; lithium carbonate; carbon mineralization; Ultra-Small-Angle; Small-Angle; Wide-Angle X-ray Scattering (USAXS/SAXS/WAXS)

\section{Introduction}

Carbon mineralization, which involves the conversion of $\mathrm{CO}_{2}$ to carbonates that are thermodynamically stable, environmentally benign, and insoluble in water, has been proposed as a pathway to safely and permanently store $\mathrm{CO}_{2}$ via natural and engineered pathways [1-10]. While various earth-abundant calcium and magnesium silicates have been extensively investigated for the permanent storage of $\mathrm{CO}_{2}[3-5,7,11,12]$ given their availability in nature [13-15], there is an increasing interest in the scalable synthesis of alternative carbonates such as lithium carbonates. Lithium carbonate is the end-product of the carbonation of lithium hydroxide, a highly reactive sorbent for $\mathrm{CO}_{2}$ capture in spacecraft and submarines. Other emerging applications include tuning the morphology of lithium carbonates synthesized from the effluent of treated Li-bearing batteries, which can be recycled back into batteries and used in ceramics and glasses. With increasing concerns around the availability of lithium that can be directly mined from the environment, there is an emerging interest in developing technologies [16-20] for closing elemental loops by combining multiple waste streams for sustainable resource and environmental management.

Some of the factors that influence the morphology of lithium carbonate are the reactive precursors and water. Previous studies have suggested that the kinetics of $\mathrm{LiOH}$ conversion to lithium 
carbonate is accelerated in the presence of water via the formation of lithium hydroxide monohydrate, $\mathrm{LiOH} \cdot \mathrm{H}_{2} \mathrm{O}$ as an intermediate [21-23], while Zho and co-workers [24] suggested that the carbonation of lithium hydroxide is an order of magnitude faster compared to lithium hydroxide monohydrate. The differences in the reactivity of lithium hydroxide monohydrate and lithium hydroxide with $\mathrm{CO}_{2}$ arise from the water released during the reaction [25]. Three times as many water molecules are produced during the carbonation of lithium hydroxide monohydrate compared to lithium hydroxide, as shown by the following reactions:

$$
\begin{gathered}
2 \mathrm{LiOH}(\mathrm{s})+\mathrm{CO}_{2}(\mathrm{~g})->\mathrm{Li}_{2} \mathrm{CO}_{3}(\mathrm{~s})+\mathrm{H}_{2} \mathrm{O}(\mathrm{g}) \\
2 \mathrm{LiOH} \cdot \mathrm{H}_{2} \mathrm{O}(\mathrm{s})+\mathrm{CO}_{2}(\mathrm{~g}) \rightarrow \mathrm{Li}_{2} \mathrm{CO}_{3}(\mathrm{~s})+3 \mathrm{H}_{2} \mathrm{O}(\mathrm{g})
\end{gathered}
$$

The role of water is important to consider, since most flue gas streams contain moisture which may lead to the formation of lithium hydroxide monohydrate as an intermediate. Since the kinetics of lithium hydroxide and lithium hydroxide monohydrate have been reported in previous studies [21-25], this study focuses on connecting the morphological and structural changes in lithium hydroxide monohydrate as it is reacted with $\mathrm{CO}_{2}$ to form lithium carbonate using multi-scale X-ray scattering measurements, which encompass Ultra-Small-Angle, Small-Angle, and Wide-Angle X-ray Scattering (USAXS/SAXS/WAXS) [26,27].

The structural changes that occur during the conversion of lithium hydroxide monohydrate to lithium carbonate, which are observed in WAXS, are related to the surface area and the size and geometry of the larger scattering features determined from the USAXS/SAXS measurements. These combined scattering techniques, which span more than four decades in spatial resolution, provide a nondestructive approach to connect nano-scale and micron-scale morphological changes with the structural changes in Angstrom scale in complex materials. The measurements reported in this study are performed in a flow-through reactor containing lithium hydroxide monohydrate and $1 \mathrm{~atm}$ of continuously flowing $\mathrm{CO}_{2}$ as the temperature is linearly ramped up from $25{ }^{\circ} \mathrm{C}$ to $500{ }^{\circ} \mathrm{C}$. The reaction-driven chemo-morphological changes as lithium hydroxide monohydrate is converted to lithium carbonate are discussed in the context of lithium carbonate conversion kinetics.

\section{Materials and Methods}

Lithium hydroxide monohydrate procured from Himedia Laboratories (West Chester, PA, USA) is loaded into a quartz capillary cell with an internal diameter of $1.3 \mathrm{~mm}$ and thickness of $0.2 \mathrm{~mm}$ (Friedrich \& Dimmock Inc., Millville, NJ, USA). The capillary cell is loaded into a sample environment cell as described by Chupas and co-workers for non-ambient experiments [28]. The starting and final temperatures are set to $26{ }^{\circ} \mathrm{C}$ and $500{ }^{\circ} \mathrm{C}$, respectively. The temperature ramp rate is set to $2.4^{\circ} \mathrm{C} / \mathrm{min}$. The partial pressure and flow rate of $\mathrm{CO}_{2}$ are set to $1 \mathrm{~atm}$ and $10 \mathrm{cc} / \mathrm{min}$, respectively. The flow rate of $\mathrm{CO}_{2}$ at $1 \mathrm{~atm}$ is set to $10 \mathrm{cc} / \mathrm{min}$.

The X-ray scattering measurements are performed at sector 9-ID at the Advanced Photon Source (APS), Argonne National Laboratory, Argonne, IL [29,30]. The USAXS, SAXS, and WAXS data are collected sequentially at each temperature of interest. The data acquisition times for the USAXS, SAXS, and WAXS measurements are 90 s, 30 s, and 30 s, respectively. Uncertainties from sampling geometry are eliminated by not changing the sample configuration in the beam path. The beam size is defined by the high-resolution X-ray slits, which are set to $0.8 \mathrm{~mm} \times 0.8 \mathrm{~mm}$ for USAXS and $0.2 \mathrm{~mm} \times 0.2 \mathrm{~mm}$ for SAXS and WAXS. This latter setting allows the detector pixel size, $172 \mu \mathrm{m} \times 172 \mu \mathrm{m}$ for both the SAXS and WAXS detectors, to provide an outgoing scattered or diffracted beam resolution comparable to those for the incident beam collimation and flux. The sample-to-detector distances for SAXS and WAXS are set to $540 \mathrm{~mm}$ and $303.5 \mathrm{~mm}$, respectively. The total X-ray flux at the sample is $10^{13}$ photon $\mathrm{mm}^{-2} \cdot \mathrm{s}^{-1}$. The $q$ values $(q=(4 \pi / \lambda) \sin \theta$, where $\lambda$ is the $X$-ray wavelength and $\theta$ is half the scattering angle) and the sample-to-detector distances (and geometry) are calibrated using silver 
behenate for SAXS and the NIST standard reference material, SRM 640d (Si) [31] for WAXS. The X-ray energy is $21.0 \mathrm{keV}$, corresponding to an X-ray wavelength of $0.59 \AA$.

The USAXS, SAXS, and WAXS data collected are reduced and analyzed using the Irena [32] and Nika [33] software packages written in Igor Pro (Wavemetrics, Portland, OR, USA). The USAXS measurement configuration is slit-smeared [34]. The slit-smeared USAXS and SAXS data are combined and analyzed to determine the morphological changes in the materials. The structural changes in the materials are determined from the WAXS data. Standard deviation uncertainties in the reduced data are represented by vertical bars in the figures (where visible). Estimated or computed standard deviation uncertainties in our fit results are typically $\pm 5 \%$ of the value, unless indicated otherwise. The surface morphological features are determined using a Hitachi 3400 Variable Pressure Scanning Electron Microscope (Hitachi High Technologies, Schaumburg, IL, USA). The pore sizes are determined using the BET method (Quantachrome Autosorb-1 BET, Boynton Beach, FL, USA).

\section{Results and Discussion}

\subsection{Structural Changes during the Carbonation of Lithium Hydroxide Monohydrate}

Significant structural changes are evident during the carbonation of lithium hydroxide monohydrate in the presence of $\mathrm{CO}_{2}$ with increasing temperature. The dehydration of lithium hydroxide monohydrate on heating is evident from the reduction in the intensity of the characteristic peak that corresponds to $d=2.67 \AA, q=2.35 \AA^{-1}$, or CuK $\alpha 2 \theta=33.54^{\circ}$ (h k 1: (-2 20$)$ ) [35] (Figure 1a). The dehydration of lithium hydroxide monohydrate is rapid on heating to temperatures above $70{ }^{\circ} \mathrm{C}$, and the characteristic peak disappears on heating to $108^{\circ} \mathrm{C}$ (Figure 1b). The onset of the lithium hydroxide peak that corresponds to $d=2.74 \AA$, $q=2.28 \AA^{-1}$, or CuK $\alpha 2 \theta=32.6^{\circ}$ (h k 1: (l $\left.\begin{array}{lll}1 & 1 & 1\end{array}\right)$ [36] occurs on heating lithium hydroxide monohydrate above $70{ }^{\circ} \mathrm{C}$ (Figure 2a). The highest integrated intensity of lithium hydroxide is noted at $147^{\circ} \mathrm{C}$, which decreases on further heating. A significant reduction in the characteristic lithium hydroxide peak is noted at temperatures above $250^{\circ} \mathrm{C}$ (Figure $2 \mathrm{~b}$ ). The characteristic lithium hydroxide peak collapses at around $450{ }^{\circ} \mathrm{C}$.

The appearance of the lithium carbonate peak at $59{ }^{\circ} \mathrm{C}$ (Figure 3a) is concurrent with the dehydration of lithium hydroxide monohydrate to form lithium hydroxide. The characteristic lithium carbonate peak that corresponds to $d=2.83 \AA, q=2.22 \AA^{-1}$, or CuK $\alpha 2 \theta=31.6^{\circ}$ (h k l: (0 0 2) ) [37] (Figure 3a) increases in intensity as the reaction temperatures increase from $71^{\circ} \mathrm{C}$ to $499^{\circ} \mathrm{C}$. The integrated intensity of the characteristic lithium carbonate peak continues to increase with an increase in temperature to about $450{ }^{\circ} \mathrm{C}$, after which it remains relatively unchanged (Figure $3 b$ ). The relatively unchanging integrated intensity of the lithium carbonate peak at temperatures above $450{ }^{\circ} \mathrm{C}$ corresponds to the collapse of the lithium hydroxide peak around $450^{\circ} \mathrm{C}$, as shown in Figure $3 \mathrm{~b}$.

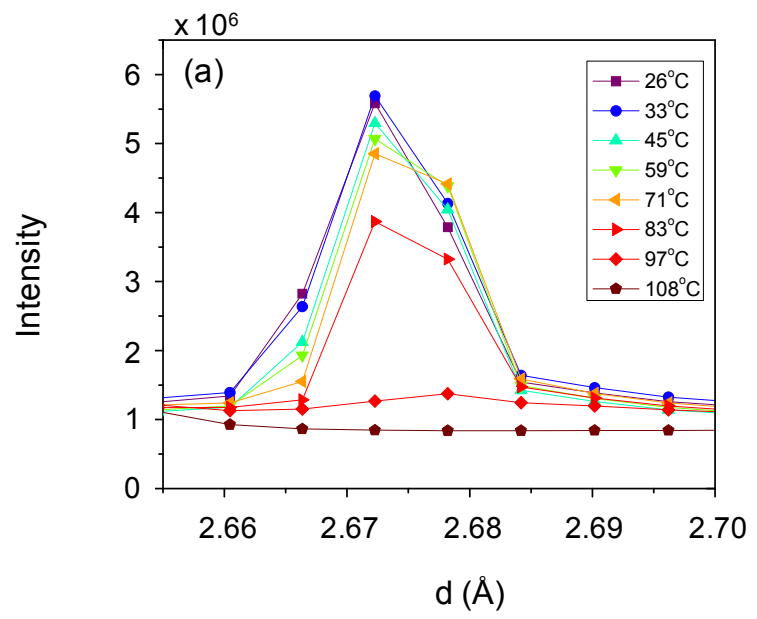

Figure 1. Cont. 


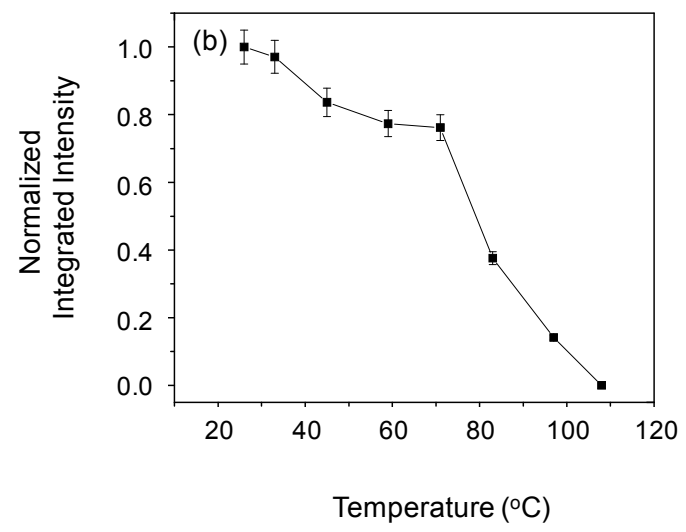

Figure 1. Changes in (a) the characteristic lithium hydroxide monohydrate peak $(d=2.67 \AA$, $q=2.35 \AA^{-1}$, or $\mathrm{CuK} \alpha 2 \theta=33.5^{\circ}$ ) and (b) the integrated peak intensity on reacting with $\mathrm{CO}_{2}$ in the temperature range of $26^{\circ} \mathrm{C}$ to $108{ }^{\circ} \mathrm{C}$. The relative integrated intensity represented in (b) is the integrated intensity of the characteristic lithium hydroxide monohydrate peak at a given temperature normalized to the integrated intensity at $26{ }^{\circ} \mathrm{C}$. Vertical bars in (b) represent estimated standard deviation uncertainties.
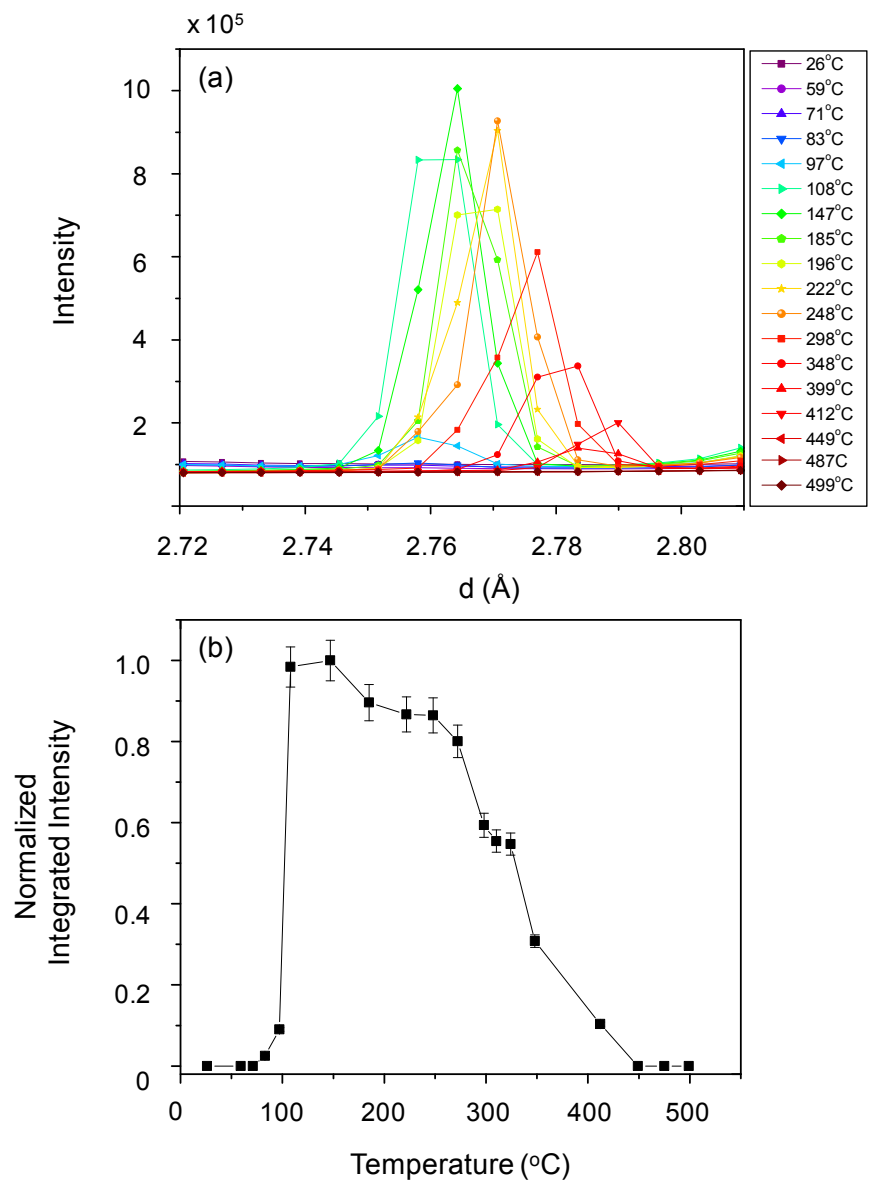

Figure 2. Changes in (a) the characteristic lithium hydroxide peak $\left(d=2.75 \AA, q=2.28 \AA^{-1}\right.$ or CuK $\alpha$ $\left.2 \theta=32.5^{\circ}\right)$ and $(\mathbf{b})$ the integrated peak intensity on reacting with $\mathrm{CO}_{2}$ in the temperature range of $26{ }^{\circ} \mathrm{C}$ to $499^{\circ} \mathrm{C}$. The relative integrated intensity represented in (b) is the integrated intensity normalized relative to the maximum integrated intensity of the lithium hydroxide peak at $108^{\circ} \mathrm{C}$. The movement of the peak to the left in (a) corresponds to the effects of thermal expansion. Vertical bars in (b) represent estimated standard deviation uncertainties. 
Following the structural changes as lithium hydroxide monohydrate is converted to lithium carbonate provides a few mechanistic insights. In an environment characterized by continuously increasing temperature, the conversion of lithium hydroxide monohydrate to lithium carbonate does not occur directly, and proceeds via the formation of lithium hydroxide. These changes in chemical composition influence the scattering contrast, which is needed to quantify the morphological changes represented by the USAXS/SAXS curves, as discussed in the following section.
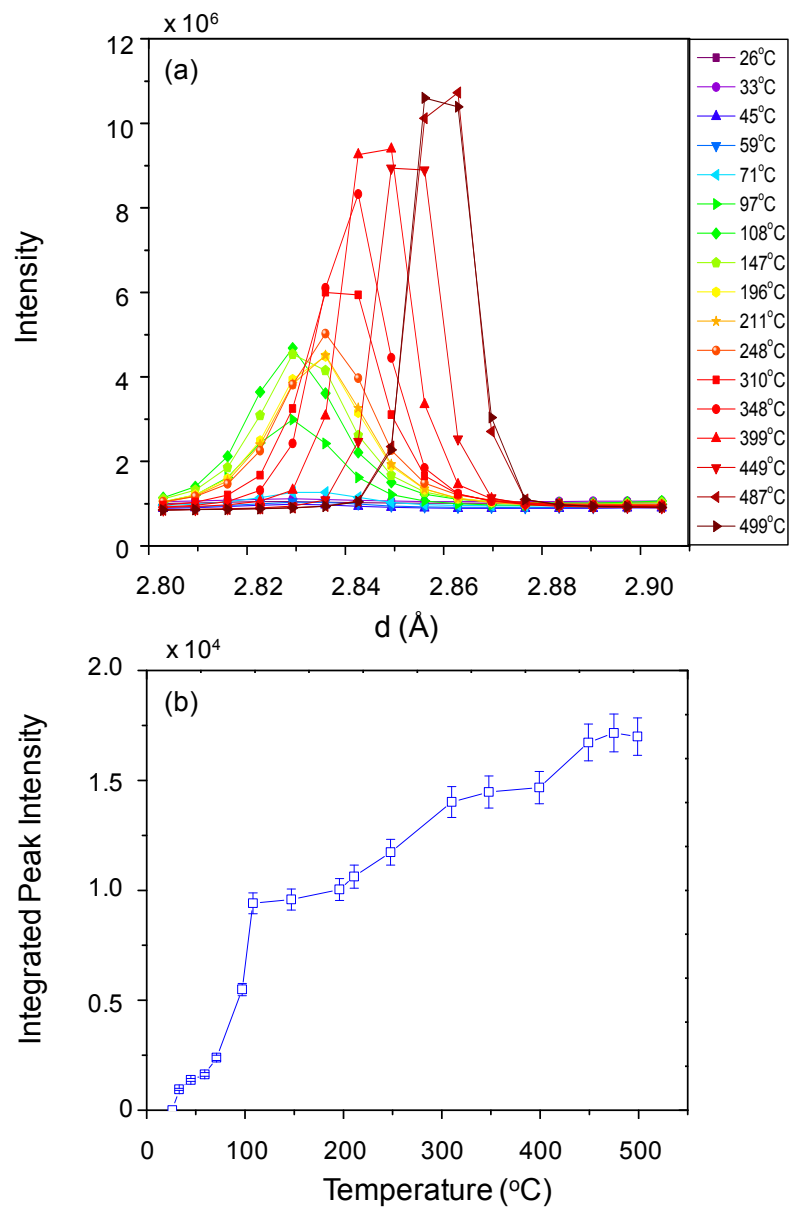

Figure 3. Changes in (a) the characteristic lithium carbonate peak $\left(d=2.83 \AA, q=2.22 \AA^{-1}\right.$, or CuK $\alpha$ $\left.2 \theta=31.6^{\circ}\right)$ and $(\mathbf{b})$ the integrated peak intensity on reacting with $\mathrm{CO}_{2}$ in the temperature range of $26^{\circ} \mathrm{C}$ to $500{ }^{\circ} \mathrm{C}$. The movement of the peak to the left in (a) corresponds to the effects of thermal expansion. Vertical bars in (b) represent estimated standard deviation uncertainties.

\subsection{Morphological Changes during the Carbonation of Lithium Hydroxide Monohydrate}

The microstructural changes are modeled from the combined Ultra-Small-Angle and Small-Angle X-ray Scattering (USAXS/SAXS) curves represented in Figure 4. Scattering as a function of $q$ is related to the Fourier transform of the real-space electron density distribution. Scattering at low and high $q$ represent the nano-scale and coarser features, respectively. A significant increase in the scattering intensity, particularly in the $q$ range of $10^{-1}$ to $10^{-3} \AA^{-1}$, is noted during the reaction of lithium hydroxide monohydrate with $\mathrm{CO}_{2}$ as the temperature is increased from $26{ }^{\circ} \mathrm{C}$ to $222{ }^{\circ} \mathrm{C}$. For example, the scattering intensity increased 50-fold from ambient temperature to $222{ }^{\circ} \mathrm{C}$ at $q=0.01 \AA^{-1}$, suggesting an increase in the scattering features. Further, a reduction in the scattering intensity is noted as the reaction temperature increases from $222^{\circ} \mathrm{C}$ to $500^{\circ} \mathrm{C}$, suggesting fewer and coarser features. The surface morphology of the lithium hydroxide monohydrate and lithium carbonate are evident from the scanning and transmission electron microscopy images shown in Figure 5. 


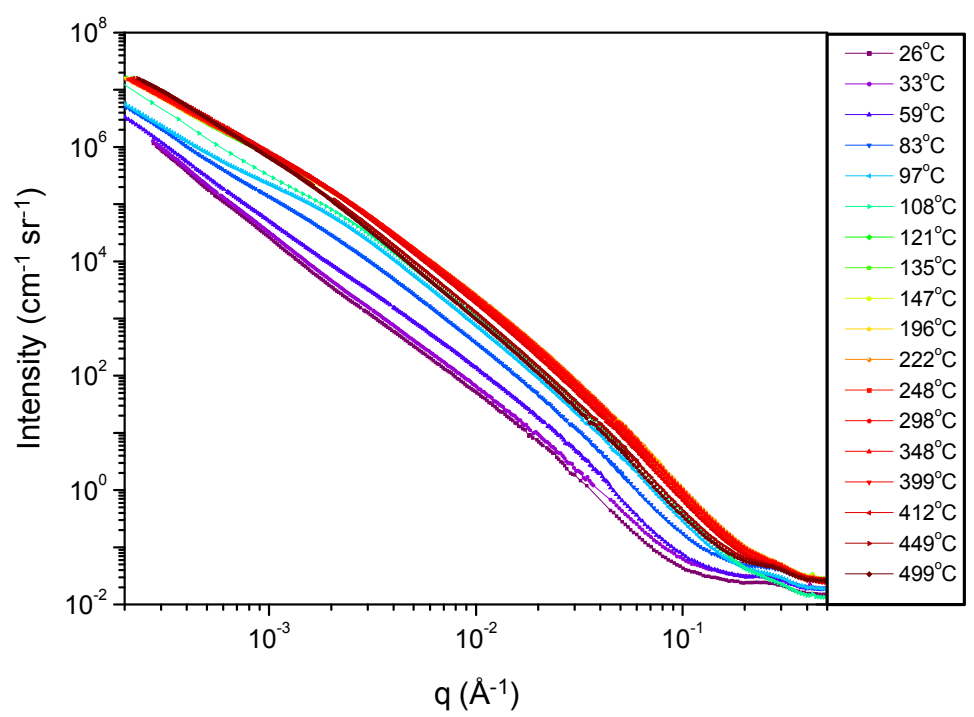

Figure 4. Changes in the combined slit-smeared Ultra-Small Angle and Small-Angle X-ray Scattering (USAXS/SAXS) data on reacting lithium hydroxide monohydrate with $\mathrm{CO}_{2}$ to form lithium carbonate in the temperature range of $26^{\circ} \mathrm{C}$ to $500{ }^{\circ} \mathrm{C}$.
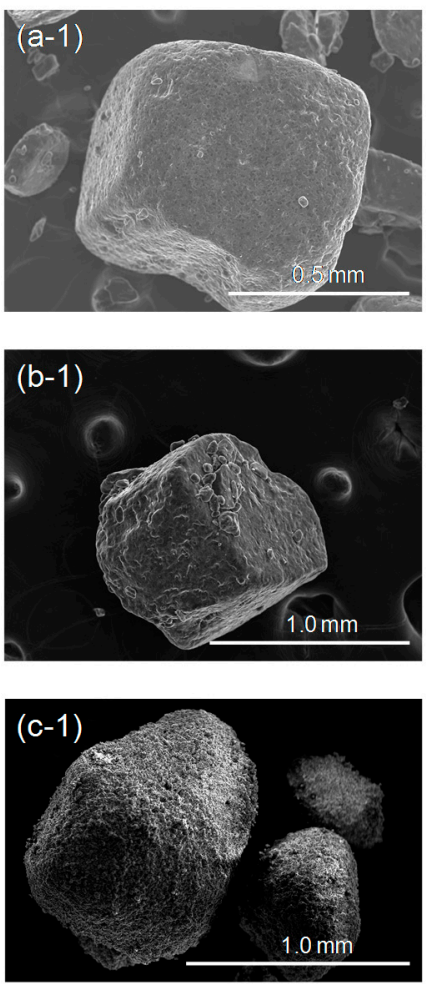
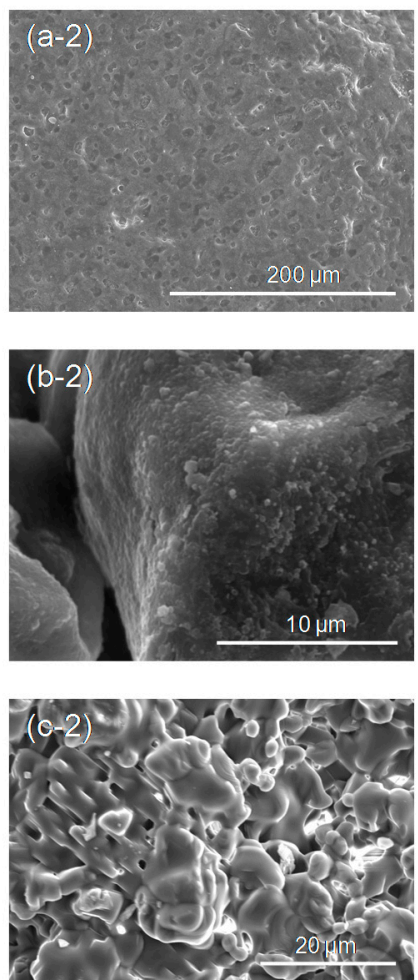

Figure 5. Microscopic views of lithium hydroxide monohydrate $((\mathbf{a}-\mathbf{1}),(\mathbf{a}-\mathbf{2}))$ as it is partially converted to lithium hydroxide at $83{ }^{\circ} \mathrm{C}((\mathbf{b}-\mathbf{1}),(\mathbf{b}-\mathbf{2}))$ and completely transformed to lithium carbonate at $500{ }^{\circ} \mathrm{C}$ $((\mathrm{c}-1),(\mathrm{c}-2))$. The surface morphology of lithium hydroxide monohydrate at $26^{\circ} \mathrm{C}$ is smoother compared to lithium hydroxide at $499^{\circ} \mathrm{C}$. The micron-scale morphology of the materials represented here show rough surface interfaces, which is indicative of fractal microstructures.

While the particle size of unreacted lithium hydroxide monohydrate is in the range of 100-700 $\mu \mathrm{m}$ (Figure 5(a-1)), nanoparticles smaller than $500 \mathrm{~nm}$ are attached to the surfaces of the large objects (Figure 5(a-2)). At $83^{\circ} \mathrm{C}$, the partial dehydration of lithium hydroxide monohydrate to produce lithium 
hydroxide results in a rougher morphological interface (Figure 5(b-1),(b-2)). Lithium carbonate formed at $499^{\circ} \mathrm{C}$ shows globular nano-scale features connected to larger-scale features (Figure 5(c-1),(c-2)). BET analyses showed that the average pore sizes of the lithium hydroxide monohydrate and lithium carbonate are in the range of 2-3 nm, with a negligible number of pores greater than $10 \mathrm{~nm}$ (Figure S1). Therefore, the nano-scale features in the $q$ range of $0.006-0.025 \AA^{-1}$ correspond to the scattering from the particles as opposed to the pores. While the microscopy images and BET data provide insights into the morphologies of these materials and the porosity, USAXS and SAXS provided quantitative microstructural information as lithium hydroxide monohydrate is converted to lithium carbonate.

\subsubsection{Contrast Variation}

Applying the appropriate contrast factor is critical for quantifying the morphological features represented by the USAXS/SAXS curves. The calibrated scattering intensity is proportional to the scattering contrast factor, $|\Delta \rho|^{2}$, which is the square of the difference in scattering length density (SLD or $\rho$ ) between the pore space and the outside solid phase. The scattering length density is determined by the chemical composition and the density of the phase, which vary as the reaction progresses. In addition to the scattering contrast factor, the measured intensity for a given population of scatterers is proportional to its overall volume fraction normalized to the total sample volume, $\Phi_{V i}$, and the mean volume of its individual pores, $V_{P i}$ (at low and intermediate $q$ ), to its surface area per unit sample volume, $S_{V i}($ at high $q$ ).

In this study, the scattering contrasts are determined based on the changing chemical composition of the reacting solid with $\mathrm{CO}_{2}$ with increasing temperature. It is evident from Figure 1 that the characteristic peak of lithium hydroxide monohydrate completely disappears on heating to $108{ }^{\circ} \mathrm{C}$ and is accompanied by the simultaneous formation of lithium hydroxide and lithium carbonate as noted in Figures 2 and 3 . The changes in the compositions of lithium hydroxide and lithium carbonate as the reaction temperature increases to $500{ }^{\circ} \mathrm{C}$ are used to determine the appropriate contrast factor for each USAXS/SAXS curve. The scattering length density, $\rho$, of lithium hydroxide monohydrate, lithium hydroxide, and lithium carbonate are $13.4 \times 10^{10}, 12.4 \times 10^{10}$, and $17.4 \times 10^{10} \mathrm{~cm}^{-2}$, respectively. Since the contrasting phase is the empty pore space with an SLD of 0 , the overall scattering contrast factor is calculated as: $\Delta \rho_{\text {overall }}^{2}=\sum_{i=1}^{3}\left(x_{i} \rho_{i}\right)^{2}$, where $x$ and $\rho$ represent the weight fraction and the scattering length density for each phase, $i$. In this study, the composition, $x_{i}$, of any or all of the three phases, which are lithium hydroxide monohydrate, lithium hydroxide, and lithium carbonate, at a given reaction temperature is represented in the determination of the overall scattering contrast factor.

The compositions of each phase are determined from the structural changes in the material from the WAXS measurements. The scattering contrast factor as a function of the reaction temperature is shown in Figure 6. As the reaction temperature increases from $26{ }^{\circ} \mathrm{C}$ to $83{ }^{\circ} \mathrm{C}$, the dehydration of lithium hydroxide monohydrate to form lithium hydroxide reduces the scattering contrast factor from $180.4 \times 10^{28} \mathrm{~m}^{-4}$ at $26^{\circ} \mathrm{C}$ to $154.1 \times 10^{28} \mathrm{~m}^{-4}$ at $83{ }^{\circ} \mathrm{C}$. As the temperature increases to $450{ }^{\circ} \mathrm{C}$, the scattering contrast factor increases to $304.1 \times 10^{28} \mathrm{~m}^{-4}$ at $450{ }^{\circ} \mathrm{C}$, which represents pure lithium carbonate. Subsequent increases in temperature do not change the lithium carbonate phase, so the scattering contrast factor is unchanged in the temperature range of $450-500{ }^{\circ} \mathrm{C}$. The determination of the appropriate model and the role of the scattering contrast factor in describing the morphological features as lithium hydroxide monohydrate is converted to lithium carbonate are discussed in the following section. 


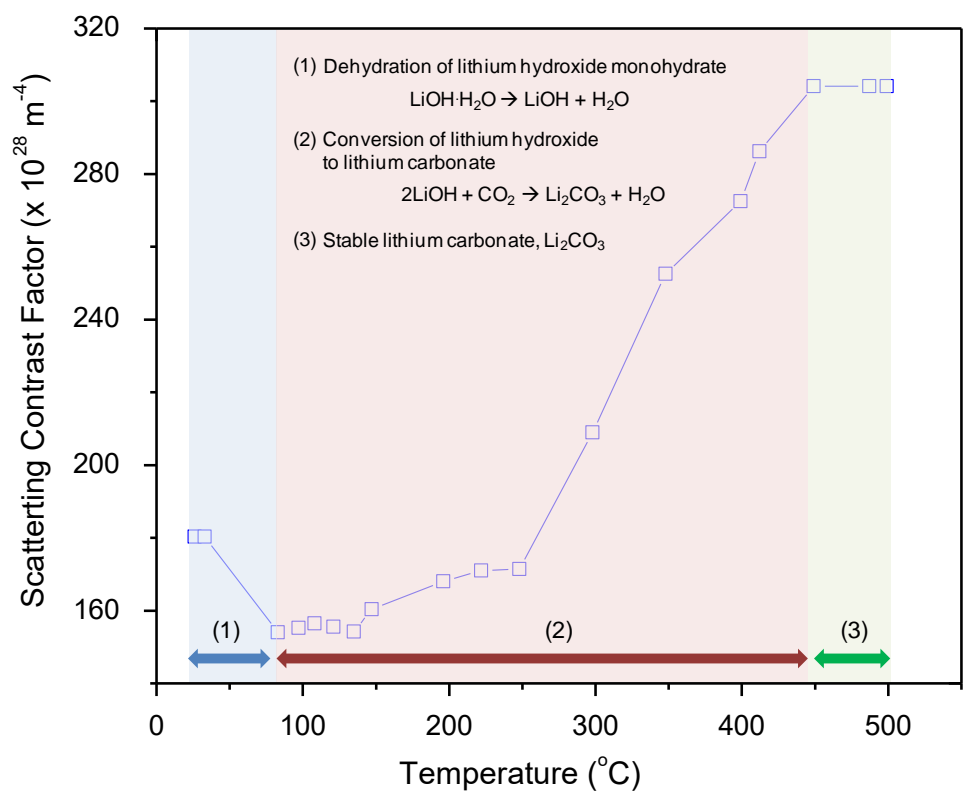

Figure 6. Calculated contrast factors for determining morphological properties as lithium hydroxide monohydrate is converted to lithium carbonate.

\subsubsection{USAXS and SAXS Data Interpretation Using the Unified Fit Model}

The combined USAXS/SAXS data is interpreted based on the unified fit model proposed by Beaucage (1995) [38]. This theory was proposed to describe multiple levels of related scattering features in complex systems. Each scattering regime is described by a Guinier, which describes the structure corresponding to a specific scattering regime, $i$, and an associated Porod power law. The Porod scattering power law corresponding to a given structural level provides insights into the associated geometry of that structural arrangement. The summation of the Guinier's exponential form and the power law for a given structural level, $i$, is represented by the following equation [38]:

$$
I(q)=\sum_{i}\left[G_{i} \exp \left(-q^{2} R_{g}^{2} / 3\right)+B_{i}\left(\frac{\left(\operatorname{erf}\left(\frac{q R_{g}}{\sqrt{6}}\right)\right)^{3}}{q}\right)^{P_{i}}\right]
$$

At the smallest $q$ in small angle scattering or the largest length scale, the residual background intensity, $B g$, has to be added to Equation (1) above to yield Equation (2) listed below:

$$
I(q)=\sum_{i}\left[G_{i} \exp \left(-q^{2} R_{g}^{2} / 3\right)+B_{i}\left(\frac{\left(\operatorname{erf}\left(\frac{q R_{g}}{\sqrt{6}}\right)\right)^{3}}{q}\right)^{P_{i}}\right]+B g
$$

In the above equations, $G_{i}$ is the Guinier exponential prefactor, $B_{i}$ is a constant prefactor for the power law scattering, $R_{g_{i}}$ is the radius of gyration, and $P_{i}$ is the power law exponent for a specific structural regime $i$. Power law exponents indicate the geometries of the scattering features. A power law exponent of 4 is indicative of a smooth surface. Power law exponents between 3 and 4 are indicative of roughness in surface fractal geometries. Mass fractals typically display power laws smaller than 3 [34]. The validity of these parameters in describing the physical system is checked using complementary techniques such as microscopy. The scanning electron microscopy images show that the morphological features to the order of microns have a smoother interface at room temperature (Figure 5(a-1),(a-2)). Increasing the reaction temperature to $83^{\circ} \mathrm{C}$ partially dehydrates lithium hydroxide monohydrate to produce lithium hydroxide and results in rougher interfaces 
(Figure 5(b-2)). The changes in the surface fractal geometry of these interfaces can be quantified using the porod slope.

One of the advantages of the unified fit approach is that it allows us to describe the morphological features for a given structural regime, $i$, using no more than two parameters each for Guinier exponential, which are $G_{i}$ and $R_{g_{i}}$, and power law fits, $B_{i}$ and $P_{i}$. In this study, the combined USAXS/SAXS curves are modeled to determine the nanostructural features and the morphology of the larger scale features. The microscopy images show that the nano-scale features can be approximated in size to globules (Figure 5(b-2),(c-2)). These features are represented by the $q$ region of $0.006-0.025 \AA^{-1}$ (Figure 4). The scattering observed in the $q$ region smaller than $0.006 \AA^{-1}$, which corresponds to larger features, is indistinguishable between the pores and particles (Figure 4). Nevertheless, the porod scattering in this region provides insights into the surface or mass fractal geometry of the scattering features.

The two unified fit parameters that directly describe the shape and the geometry of the scattering features are the guinier radius, $R_{g}$, and the porod slope, $P$, respectively. In the larger $q$-region of $0.006-0.025 \AA^{-1}, R_{g}$ describes the radius of gyration of the nanoparticles, and the porod slope, $P$, provides insights into the surface or mass fractal geometry of the scattering objects. The geometric radius of the sphere is related to the radius of gyration of a sphere through the following relationship: $R_{\text {geo }}=\sqrt{\frac{3}{5}} R_{g}$. In the smaller $q$-region, where the scattering from the pores and particles is indistinguishable, describing the size and shape of the scattering objects using the Guinier exponential prefactor does not provide physically meaningful insights into the morphology. Therefore, in this region, the scattering is described only using the Porod scattering slope. Further, the scattering from the nano-scale pores is independent of the scattering from the larger objects at smaller $q$, so the $R_{g, c u t o f f}$ function in Irena is implemented.

In the larger $q$-region of $0.006-0.025 \AA^{-1}$, which corresponds to the nanoparticles, the porod slope, $P$, across the entire temperature range of $26-500{ }^{\circ} \mathrm{C}$ is 4 , indicating that the surfaces of the nanoparticles are smooth. For smooth interfaces, the average surface area, $S$, the average number of particles per unit volume, $N$, the scattering contrast factor, $\Delta \rho^{2}$, and the scattering vector, $q$, are related to the scattering intensity, $I(q)$, through the following relationship:

$$
I(q)=2 \pi N \Delta \rho^{2} S q^{-4} .
$$

In addition, the volume fraction for a given structural level can be determined independently of the morphology or the geometric arrangement [39], using the following relationship:

$$
Q_{P}=\int_{0}^{\infty} Q^{2} \frac{d \Sigma}{d \Omega}(Q) d Q=2 \pi^{2} \varphi(1-\varphi)|\Delta \rho|^{2} .
$$

Here $Q_{P}, \varphi$, and $\Delta \rho^{2}$ represent the scattering invariant, the total nanoparticle volume fraction, and the scattering contrast factor, respectively.

\subsubsection{Quantification of the Morphological Features from Unified Fit Analyses}

The morphological information from the unified fit model in conjunction with the changes in the structure of the lithium hydroxide monohydrate as it is reacted with $\mathrm{CO}_{2}$ to form lithium carbonate provide important insights into reaction driven chemo-morphological changes in complex materials. At the nanostructural level in the $q$ range of $0.006-0.025 \AA^{-1}$, the porod slope of 4 allows us to apply Equation (3) to determine the specific surface area of the nanoparticles. The dehydration of lithium hydroxide monohydrate to produce lithium hydroxide reduces the Guinier radius of the nanoparticles, $R_{g}$, from $30 \mathrm{~nm}$ at $26^{\circ} \mathrm{C}$ to $23 \mathrm{~nm}$ at $83^{\circ} \mathrm{C}$, and increases the specific surface area of these nanoparticles from $1938 \mathrm{~cm}^{2} / \mathrm{cm}^{3}$ to $16,180 \mathrm{~cm}^{2} / \mathrm{cm}^{3}$ (Figure $7 \mathrm{a}$ ).

In this study, the scattering invariant, which represents the total integrated scattering intensity in the $q$ range 0.006-0.025 $\AA^{-1}$, as shown in Equation (4) also increases as the dehydration of lithium 
hydroxide monohydrate produces lithium hydroxide in the range of $26{ }^{\circ} \mathrm{C}$ to $83{ }^{\circ} \mathrm{C}$ (Figure $7 \mathrm{~b}$ ). The corresponding increase in the volumes of the nanoparticles from $0.1 \%$ to $0.6 \%$ is noted as the reaction temperature is increased from $26{ }^{\circ} \mathrm{C}$ to $83^{\circ} \mathrm{C}$ (Figure $7 \mathrm{~b}$ ). In this temperature range, the increase in the nanoparticle volume distribution and the reduction in the average nanoparticle size are shown in Figure 8. Noda and Koga [25] suggested that the formation of lithium carbonate from lithium hydroxide monohydrate at lower temperatures may proceed via the presence of a liquid phase at the reaction interface. However, in our reaction system, the gas flow rates are sufficiently high to drive away the water formed during the dehydration process.
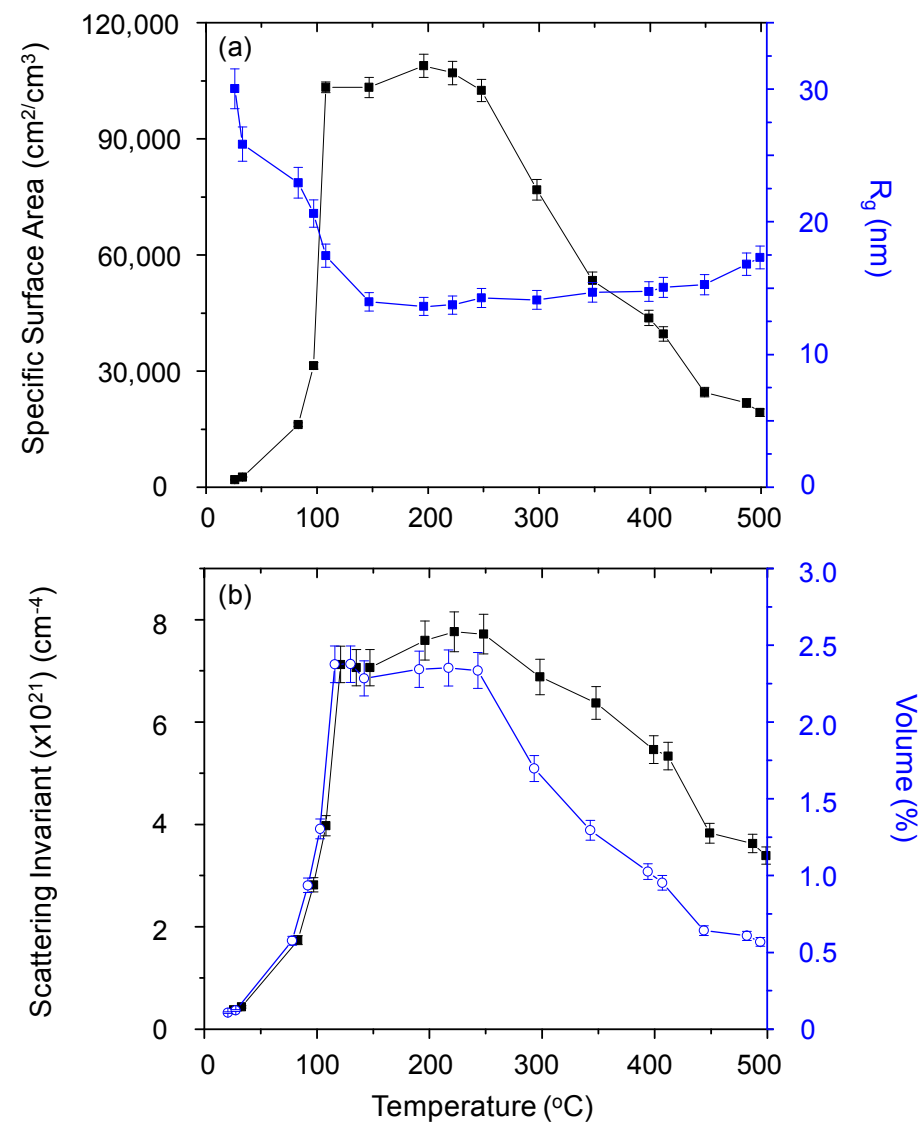

Figure 7. Changes in the (a) specific surface area and the radius of gyration, $R_{g}$, of the nano-scale particles and (b) the scattering invariant and the volume of nanoparticles as lithium hydroxide monohydrate is converted to lithium carbonate.

In the temperature range of $100{ }^{\circ} \mathrm{C}$ to $150{ }^{\circ} \mathrm{C}$, changes in the intensity and integrated intensity of the lithium hydroxide and lithium carbonate peaks (Figures 2 and 3) show that the lithium hydroxide peak reaches a maximum intensity at $147^{\circ} \mathrm{C}$ while the lithium carbonate peak continues to increase in intensity. These data suggest that the composition of lithium hydroxide dominates lithium carbonate in the temperature regime of $100{ }^{\circ} \mathrm{C}$ to $150{ }^{\circ} \mathrm{C}$. The radius of gyration of the nanoparticles at $97^{\circ} \mathrm{C}$ decreases from $20 \mathrm{~nm}$ to $14 \mathrm{~nm}$ at $147^{\circ} \mathrm{C}$, while the corresponding surface areas increase from 31,370 to $103,370 \mathrm{~cm}^{2} / \mathrm{cm}^{3}$. The increase in the volume fractions as the sizes of the nanoparticles become smaller in the temperature range of $100-147^{\circ} \mathrm{C}$ is noted in Figure 8. Noda and Koga [25] alluded to morphological self-regulation during the conversion of lithium hydroxide to lithium carbonate based on their kinetic models without providing quantitative microstructural insights. Our data suggest that dehydration decreases the size of the reacting particles, which in turn reduces mass transfer limitations allowing $\mathrm{CO}_{2}$ to access the core of the particle. The enhanced surface area and volume fractions of the reacting nanoparticles also provide $\mathrm{CO}_{2}$ with greater access to the reactive sites. 
At temperatures in the range of $196^{\circ} \mathrm{C}$ to $450{ }^{\circ} \mathrm{C}$, the increase in the intensity of the lithium carbonate peak (Figure 3) corresponds to the reduced intensity of the lithium hydroxide peak (Figure 2). The conversion of lithium hydroxide to lithium carbonate increases the Guinier radius, $R_{g}$, of the particles from $14 \mathrm{~nm}$ at $196{ }^{\circ} \mathrm{C}$ to $15 \mathrm{~nm}$ at $449{ }^{\circ} \mathrm{C}$. A significant reduction in the surface area, from $108,900 \mathrm{~cm}^{2} / \mathrm{cm}^{3}$ at $196{ }^{\circ} \mathrm{C}$ to $24,560 \mathrm{~cm}^{2} / \mathrm{cm}^{3}$ at $449{ }^{\circ} \mathrm{C}$, is noted. Further, the volume fraction of the nanoparticles changes from $2.34 \%$ to $0.64 \%$. These data indicate the formation of a dense lithium carbonate phase with reduced surface area, which is consistent with the observations reported by Noda and Koga [25]. At $449^{\circ} \mathrm{C}$, the lithium hydroxide phase completely disappears and the scattering is entirely from the lithium carbonate phase (Figures 2 and 3). As the reaction temperature is increased from $449^{\circ} \mathrm{C}$ to $499^{\circ} \mathrm{C}$, the agglomeration of the lithium carbonate nanoparticles is noted from the increase in the Guinier radius from $15 \mathrm{~nm}$ to $17 \mathrm{~nm}$, and the reduction in the surface area from $24,560 \mathrm{~cm}^{2} / \mathrm{cm}^{3}$ at $449{ }^{\circ} \mathrm{C}$ to $19,280 \mathrm{~cm}^{2} / \mathrm{cm}^{3}$ at $499{ }^{\circ} \mathrm{C}$. The shift in the nanoparticle volume distribution towards larger sizes as the reaction temperature increases from $449^{\circ} \mathrm{C}$ to $499^{\circ} \mathrm{C}$ is also evident in Figure 8.

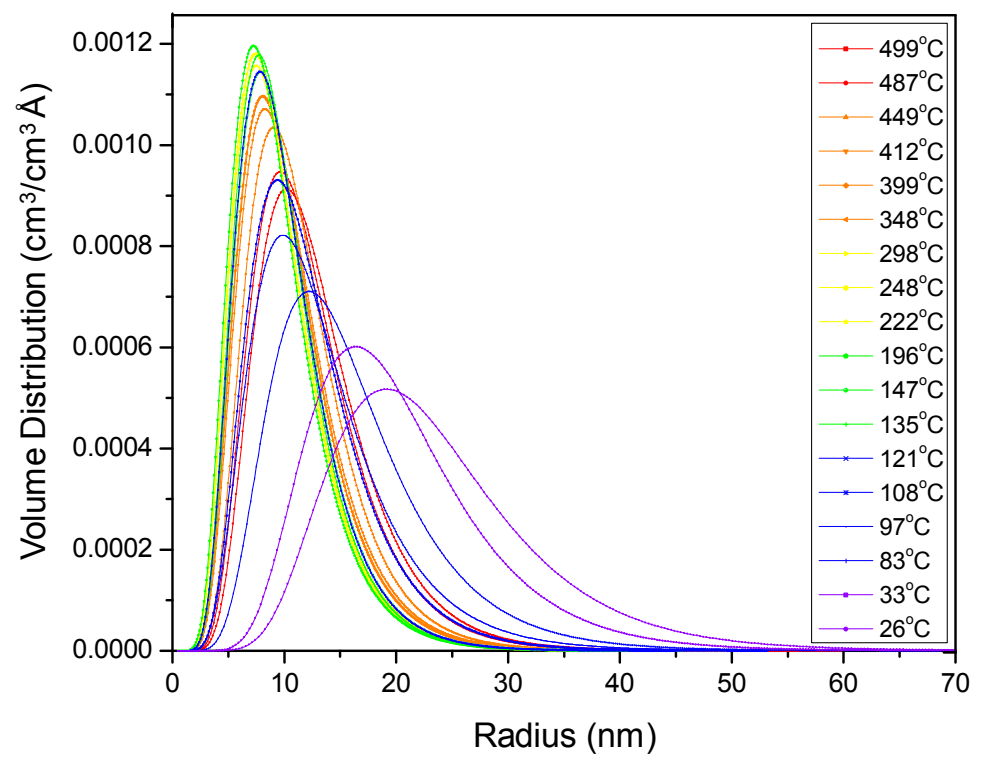

Figure 8. Changes in the nanoparticle volume distribution as lithium hydroxide monohydrate reacts with $\mathrm{CO}_{2}$ to form lithium carbonate in the temperature range of $26^{\circ} \mathrm{C}$ to $500{ }^{\circ} \mathrm{C}$.

In addition to the changes in the nanoparticle structure, insights into the micron-scale morphology are obtained from the scattering data in the $q$ range of $0.0002-0.006 \AA^{-1}$. As discussed in Section 3.2.2, the scattering observed in this region is indistinguishable between the pores and the particles, so describing the size of the scattering objects using a Guinier radius is not physically meaningful. Instead, the porod exponent provides insights into the fractal geometry of the larger features and the evolution of this geometry as lithium hydroxide monohydrate is converted to lithium carbonate.

The porod slope for the larger scattering features in the lower $\mathrm{Q}$ regime of $0.006 \AA^{-1}$ to $0.002 \AA^{-1}$ provides insights into relative smoothness or roughness of the larger interfaces as lithium hydroxide monohydrate is converted to lithium hydroxide and then to lithium carbonate. The porod slope of the larger scattering features at $26^{\circ} \mathrm{C}$ is 3.7 , and dehydration results in a rougher surface characterized by a porod slope around 3 (Figure 9). As the temperature increases from $108{ }^{\circ} \mathrm{C}$ to $499^{\circ} \mathrm{C}$, which is characterized by the depletion of the lithium hydroxide phase and formation of lithium carbonate, the increase in the porod slope to 3.4 suggests enhanced smoothness of the surface fractal geometry (Figure 9). These data suggest that the dehydration of lithium hydroxide monohydrate results in rougher nano-scale interfaces, while the formation of lithium carbonate results in smoother surface fractal interfaces at the micron scale. 


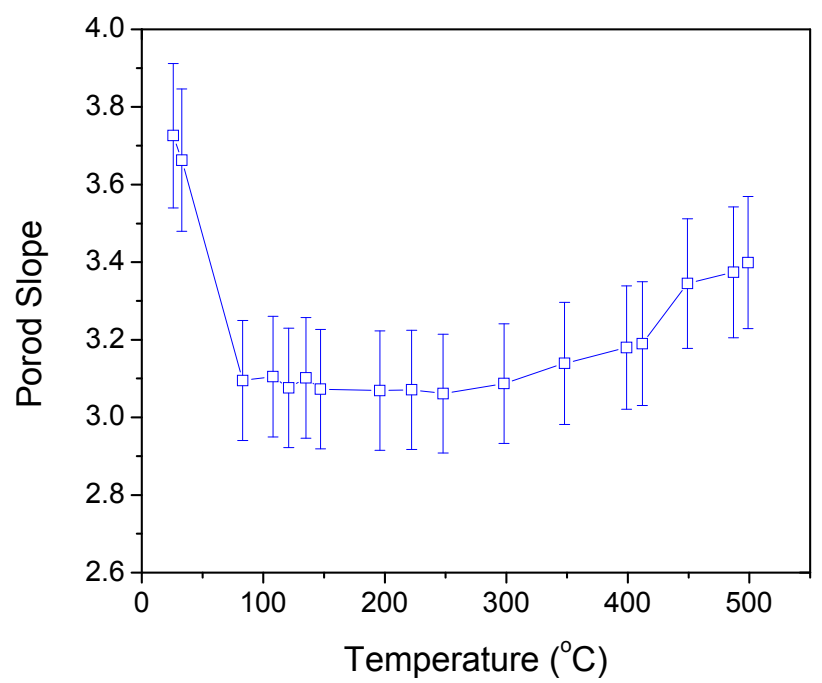

Figure 9. Changes in the porod slope of the scattering features in the $q$ range of $0.0002-0.006 \AA^{-1}$. Porod slope in the range of 3-4 indicates a surface fractal, with 4 being a smooth interface. As the reaction temperature increases to $100^{\circ} \mathrm{C}$, the dehydration of lithium hydroxide monohydrate to produce lithium hydroxide results in a rougher interface. Progressive growth of lithium carbonate with increase in reaction temperature above $100{ }^{\circ} \mathrm{C}$ reduces the roughness of the interface.

\section{Conclusions}

In this study, the morphological and chemical changes as lithium hydroxide monohydrate is converted to lithium carbonate are determined using in-operando USAXS/SAXS/WAXS measurements. The increase in the reaction temperature from $26{ }^{\circ} \mathrm{C}$ to $147{ }^{\circ} \mathrm{C}$ reduces the Guinier radius of the nanoparticles from $30 \mathrm{~nm}$ to $14 \mathrm{~nm}$, while the surface area and the volume fraction of these features increases. The dehydration of lithium hydroxide monohydrate to form lithium hydroxide and the onset of lithium carbonate is noted in this temperature range. At higher reaction temperatures in the range of $222^{\circ} \mathrm{C}$ and $500{ }^{\circ} \mathrm{C}$, formation of the denser lithium carbonate phase reduces the surface area and volume fraction of the nanoparticles, and increases the Guinier radius of the nanoparticles from $14 \mathrm{~nm}$ to $17 \mathrm{~nm}$. Further, the interfaces at the nanoparticles are smooth, while the larger scattering features at smaller $q$ are characterized by surface fractals representing rough interfaces. The dehydration of lithium hydroxide monohydrate to form lithium hydroxide increases the surface roughness, while the progressive formation of lithium carbonate at higher temperatures results in smoother interfaces. These in operando scattering measurements show the chemo-morphological feedbacks during the conversion of lithium hydroxide monohydrate to lithium carbonate, and the potential for tuning the lithium carbonate's morphology by changing the reaction temperature, gas composition, and the moisture content for various industrial applications.

Supplementary Materials: The following are available online at www.mdpi.com/2075-163X/7/9/169/s1. Figure S1: The pore volume distributions of lithium hydroxide monohydrate and lithium carbonate determined using the BET method.

Acknowledgments: The author would like to acknowledge the assistance of William Schneider and Meishen Liu in collecting the electron microscopy data. G.G. gratefully acknowledges the support of the Wisconsin Alumni Research Foundation, and the assistance of Jan Ilavsky and Ross Andrews, X-ray Science Division, Argonne National Laboratory, for providing experimental support for the combined USAXS/SAXS/WAXS measurements at the Advanced Photon Source. The use of the Advanced Photon Source, an Office of Science User Facility operated for the U.S. Department of Energy (DOE) Office of Science by Argonne National Laboratory, is supported by the U.S. DOE under Contract DE-AC02-06CH11357.

Conflicts of Interest: The author declares no conflict of interest. 


\section{References}

1. Lackner, K.S.; Wendt, C.H.; Butt, D.P.; Joyce, E.L., Jr.; Sharp, D.H. Carbon dioxide disposal in carbonate minerals. Energy 1995, 20, 1153-1170. [CrossRef]

2. Oelkers, E.H.; Gislason, S.R.; Matter, J. Mineral carbonation of $\mathrm{CO}_{2}$. Elements 2008, 4, 333-337. [CrossRef]

3. Park, A.H.A.; Jadhav, R.; Fan, L.S. $\mathrm{CO}_{2}$ mineral sequestration: Chemically enhanced aqueous carbonation of serpentine. Can. J. Chem. Eng. 2003, 81, 885-890. [CrossRef]

4. Park, A.H.A.; Fan, L.S. $\mathrm{CO}_{2}$ mineral sequestration: Physically activated dissolution of serpentine and $\mathrm{pH}$ swing process. Chem. Eng. Sci. 2004, 59, 5241-5247. [CrossRef]

5. Gerdemann, S.J.; O'Connor, W.K.; Dahlin, D.C.; Penner, L.R.; Rush, H. Ex situ aqueous mineral carbonation. Environ. Sci. Technol. 2007, 41, 2587-2593. [CrossRef] [PubMed]

6. Gadikota, G.; Park, A.H.A. Accelerated Carbonation of Ca- and Mg-Bearing Minerals and Industrial Wastes Using $\mathrm{CO}_{2}$. In Carbon Dioxide Utilization: Closing the Carbon Cycle; Styring, P., Quadrelli, A., Armstrong, K., Eds.; Elsevier: Oxford, UK, 2014.

7. Gadikota, G.; Matter, J.; Kelemen, P.; Park, A.A. Chemical and morphological changes during olivine carbonation for $\mathrm{CO}_{2}$ storage in the presence of $\mathrm{NaCl}$ and $\mathrm{NaHCO}_{3}$. Phys. Chem. Chem. Phys. 2014, 16, 4679-4693. [CrossRef] [PubMed]

8. Pan, S.-Y.; Chang, E.; Chiang, P.-C. $\mathrm{CO}_{2}$ Capture by Accelerated Carbonation of Alkaline Wastes: A Review on Its Principles and Applications. Aerosol Air Qual. Res. 2012, 12, 770-791. [CrossRef]

9. Gadikota, G.; Swanson, E.J.; Zhao, H.; Park, A.H.A. Experimental design and data analysis for accurate estimation of reaction kinetics and conversion for carbon mineralization. Ind. Eng. Chem. Res. 2014, 53, 6664-6676. [CrossRef]

10. Gadikota, G. Commentary: Ex Situ Aqueous Mineral Carbonation. Front. Energy Res. 2016, 4, 21. [CrossRef]

11. Zhao, H.; Park, Y.; Lee, D.H.; Park, A.-H.A. Tuning the dissolution kinetics of wollastonite via chelating agents for $\mathrm{CO}_{2}$ sequestration with integrated synthesis of precipitated calcium carbonates. Phys. Chem. Chem. Phys. 2013, 15, 15185-15192. [CrossRef] [PubMed]

12. O'Connor, W.K.; Dahlin, D.C.; Rush, G.E.; Gerdemann, S.J.; Nilsen, D.N. Final Report: Aqueous Mineral Carbonation: DOE/ARC-TR-04-002; National Energy Technology Laboratory: Albany, OR, USA, 2004.

13. Matter, J.M.; Kelemen, P.B. Permanent storage of carbon dioxide in geological reservoirs by mineral carbonation. Nat. Geosci. 2009, 2, 837-841. [CrossRef]

14. Kelemen, P.B.; Matter, J.; Streit, E.E.; Rudge, J.F.; Curry, W.B.; Blusztajn, J. Rates and mechanisms of mineral carbonation in peridotite: Natural processes and recipes for enhanced, in situ $\mathrm{CO}_{2}$ capture and storage. Annu. Rev. Earth Planet. Sci. 2011, 39, 545-576. [CrossRef]

15. Gadikota, G.; Fricker, K.; Jang, S.-H.; Park, A.-H.A. Carbonation of Silicate Minerals and Industrial Wastes and Their Potential Use as. In Advances in $\mathrm{CO}_{2}$ Capture, Sequestration, and Conversion; Jin, F., He, L.-N., Hu, Y.H., Eds.; American Chemical Society: Washington, DC, USA, 2015; pp. 295-322.

16. Contestabile, M.; Panero, S.; Scrosati, B. A laboratory-scale lithium battery recycling process. J. Power Sources 1999, 83, 75-78. [CrossRef]

17. Granata, G.; Moscardini, E.; Pagnanelli, F.; Trabucco, F.; Toro, L. Product recovery from Li-ion battery wastes coming from an industrial pre-treatment plant: Lab scale tests and process simulations. J. Power Sources 2012, 206, 393-401. [CrossRef]

18. Richa, K.; Babbitt, C.W.; Gaustad, G.; Wang, X. A future perspective on lithium-ion battery waste flows from electric vehicles. Resour. Conserv. Recycl. 2014, 83, 63-76. [CrossRef]

19. Gaines, L. The future of automotive lithium-ion battery recycling: Charting a sustainable course. Sustain. Mater. Technol. 2014, 1, 2-7. [CrossRef]

20. Nan, J.; Han, D.; Zuo, X. Recovery of metal values from spent lithium-ion batteries with chemical deposition and solvent extraction. J. Power Sources 2005, 152, 278-284. [CrossRef]

21. Williams, D.D.; Miller, R.R. Effect of Water Vapor on the $\mathrm{LiOH}-\mathrm{CO}_{2}$ Reaction. Dynamic Isothermal System. Ind. Eng. Chem. Fundam. 1970, 9, 454-457. [CrossRef]

22. Boryta, D.A.; Maas, A.J. Factors Influencing Rate of Carbon Dioxide Reaction with Lithium Hydroxide. Ind. Eng. Chem. Process Des. Dev. 1971, 10, 489-494. [CrossRef]

23. Wang, T.C.; Bricker, J.L. Combined temperature and water vapor effects on the lithium hydroxide-carbon dioxide reaction in underwater life support systems. Environ. Int. 1979, 2, 425-430. [CrossRef] 
24. Zho, Z.; Chashchin, V.A.; Vishnyakov, A.V. Carbonization kinetics of lithium hydroxide and its monohydrate. Theor. Found. Chem. Eng. 2007, 41, 577-584. [CrossRef]

25. Noda, Y.; Koga, N. Phenomenological kinetics of the carbonation reaction of lithium hydroxide monohydrate: Role of surface product layer and possible existence of a liquid phase. J. Phys. Chem. C 2014, 118, 5424-5436. [CrossRef]

26. Gadikota, G.; Zhang, F.; Allen, A.J. Towards understanding the microstructural and structural changes in natural hierarchical materials for energy recovery: In-operando multi-scale $\mathrm{X}$-ray scattering characterization of Na- and Ca-montmorillonite on heating to $1150{ }^{\circ} \mathrm{C}$. Fuel 2017, 196, 195-209. [CrossRef]

27. Gadikota, G.; Allen, A.J. Microstructural and structural characterization of materials for $\mathrm{CO}_{2}$ storage using multi-scale scattering methods. In Materials and Processes for $\mathrm{CO}_{2}$ Capture, Conversion, and Sequestration; Li, L., Wong-Ng, W., Eds.; John Wiley \& Sons: Hoboken, NJ, USA, 2017.

28. Chupas, P.J.; Chapman, K.W.; Kurtz, C.; Hanson, J.C.; Lee, P.L.; Grey, C.P. A versatile sample-environment cell for non-ambient X-ray scattering experiments. J. Appl. Crystallogr. 2008, 41, 822-824. [CrossRef]

29. Ilavsky, J.; Jemian, P.R.; Allen, A.J.; Zhang, F.; Levine, L.E.; Long, G.G. Ultra-small-angle X-ray scattering at the Advanced Photon Source. J. Appl. Crystallogr. 2009, 42, 469-479. [CrossRef]

30. Ilavsky, J.; Zhang, F.; Allen, A.J.; Levine, L.E.; Jemian, P.R.; Long, G.G. Ultra-small-angle X-ray scattering instrument at the advanced photon source: History, recent development, and current status. Metall. Mater. Trans. A 2013, 44, 68-76. [CrossRef]

31. Black, D.R.; Windover, D.; Henins, A.; Gil, D.; Filliben, J.; Cline, J.P. Certification of nist standard reference material 640d. Powder Diffr. 2010, 25, 187-190. [CrossRef]

32. Ilavsky, J.; Jemian, P.R. Irena: Tool suite for modeling and analysis of small-angle scattering. J. Appl. Crystallogr. 2009, 42, 347-353. [CrossRef]

33. Ilavsky, J. Nika: Software for two-dimensional data reduction. J. Appl. Crystallogr. 2012, 45, 324-328. [CrossRef]

34. Beaucage, G. Small-Angle Scattering from Polymeric Mass Fractals of Arbitrary Mass-Fractal Dimension. J. Appl. Crystallogr. 1996, 29, 134-146. [CrossRef]

35. Alcock, N.W. Refinement of the crystal structure of lithium hydroxide monohydrate. Acta Crystallogr. Sect. B Struct. Crystallogr. Cryst. Chem. 1971, 27, 1682-1683. [CrossRef]

36. Dachs, H. Bestimmung der Lage des Wasserstoffs in LiOH durch Neutronenbeugung. Z. Krist. Mater. 1959, 112, 60-67. [CrossRef]

37. Zemann, J. Die Kristallstruktur von $\mathrm{Li}_{2} \mathrm{CO}_{3}$. Acta Crystallogr. 1957, 10, 664-666. [CrossRef]

38. Beaucage, G. Approximations leading to a unified exponential power-law approach to small-angle scattering. J. Appl. Crystallogr. 1995, 28, 717-728. [CrossRef]

39. Glatter, O.; Kratky, O. Small Angle Scattering; Academic: New York, NY, USA, 1982. 